area. Owing to the friction which the wind experiences in passing over the surface of the eartb, however, this upward current conld exist at its maximum only at a considerable height. But it is important to observe that there may frequently be a considerable amount of current upwards in the regions where birds "hover," at least in the neighbourhood of a cyclonic vortex. But how much lifting force is necessary to sustain, say a gull, in the air? A gull moves its wings in ordinary flight at from 160 to 200 (double) strokes per minute, and reckoning I2 inches as the greatest vertical depth through which the bird can raise itself by one (double) stroke, we find that it possesses the power of raising itself about 180 vertical feet per minute. This, however, is less than one-half of the rate at which we have found the currents to rise near the centre of a cyclonic depression. From this we may judge it is likely enough that birds "hover," or suspend themselves motionless in the air through the influence of upgoing currents, which are masked to our observation by the fresh winds which accompany them.

A kestrel may, however, support itself largely by its peculiar quivering play of the wings, and I. think it must be difficult to determine how much support a bird may contribute by such motion, when at a height where it is difficult to observe it.

I have frequently observed gulls "hovering " upon currents of air $\mathrm{xhich}$ were heaped up by the wind striking obliquely upon a rising coast line, in uhich case the head is turned at an angle to the general direction of the wind, so as to face the heaped-up and rising currents. Such passing over irregular ground are irregular or gusty, and tax the bird's utmost muscular agility to prevent a sudden lateral turning to leeward, in which case the rapid flight with the currents may be compared to the fall of a stone tis the ground. The same upward direction to the atmospheric currents must be imparted by the cortracting sides of a converging valley. But when such local forces derive aid from the upward currents peculiar to cyclonic winds, atmospheric conditions favourable to "hovering" must, I think, frequently occur.

On the other hand, I cannot conceive it to be possible for birds (and I do not think that the third chapter of the "Reign of Law," gives any sufficient explanation) to sustain themselves motionless on currents of air which are purely horizontal, for in such case there is nothing to compensate-when the wings are slanted at the necessary angle to prevent falling-the backward horizontal force, and the creature must inevitably be driven backwards.

Dundee, February 5

ON August I2, I88I, I observed a hawk maintaining an apparently stationary position at a height of about 200 feet above the surface of flat ground. He was as a matter of course facing the wind, which blew, if I remember rightiy, from the west. For the most part his wings remained motionless, but now and then be fluttered them for a little while. This was over the sensibly level plain which lies between Machrihanish Bay and Campbeltown Loch, at the southern end of the Mull of Cantire, and, curiously enough, on or close to the Duke of Argyll's property. The exact spot was about a mile and a half eastwards from Machrihanish Bay, and about three-quarters of a mile northwards from the southern boundary of the plain. There could not be any "slant upward current," such as Mr. Airy supposes, maintaining him in that position; at any rate, there was no sloping ground near.

I watched this bird for about ten minutes, and he verified in a remarkable manner the views I had held on this subject for many years, namely, that, given a steady wind blowing with a velocity which lies somewhere between certain possibly calculable limits, a hawk can remain fcr a time apparently motionless above a point; he $\mathrm{i}$;, in reality, descending a slighily inclined plane, and requires to recover vertically lost ground by the occasional use of his wings.

Cardiff, January 30

IN the letters on the above subject that have appeared in some recent numbers of NATURE, the writers lead us to believe that a current of air is necessary to enable a bird to " hover" or retain when on wing a motionless position. My observations lead to an opposite conclusion, as I bave often seen both hawks and terns remain steadily poised, when there was not a breath of wind. That there was no wird where the birds (terns) were, was shown by their heads, when hovering, teing turned in different directions, although at only a short dist nnce from each other.
Generally, if not always on these occasions, I noticed that tle birds spread out their tails in a more or less depressed fosition, as if to counteract any forward movement likely to be caused by the wing-motion.

4, Addison Gardens, February 3

IN reading the letters published in your last issues of NATURE with regard to the hovering of birds, it struck me that a very similar thing can be seen sometimes, among inanimate objects when an imperfect attempt is made to cause "ducks and drakes' with a flat stone. I have cominonly noticed that the missile curves sharply upwards and for a moment "hovers" as it were' in mid-air before dropping. In this case and also in the similar one of the motion of the boomerang, the slanting upwards and the apparent hovering do not require, and need not be due to, upward currents, but merely depend upon the force of a horizontal current of air meeting the inherent force of the moving body. It is not unreasonable to suppose a similar simple solution of bird hovering.

Linnæus Street, Hull, February 3

Is there not an error in the letter of NATURE (p. 312)? The writer there suggests, as it seems to me, that a bird could maintain a position of rest, with respect to the earth, by a suitable slope of the wings against a horizontal wind. Now, as I pointed out in NATURE, vol, xxiii. p. 78 , such lifting action on the part of the wind can only take place in the interval between the time when the bird is first launched from the cliff, and the time when it has by friction attained the velocity of the wind. That this interval is not a long one, is shown when balloons or other objects are launched.

[It may be well to notice, that if there were no friction there is no lifting power; so that if we object to the above, that "the bird gives such a very small friction with the wind," we thereby do away to the same extent with the lifting power; just as a frictionless ship in a constant stream would be unmoved. were it sufficiently tapering.]

From the above considerations I have been compelled, since writing my last letter, to ascribe the hovering power of birds-

I. To the "exquisite muscular sense" by which they can take advantage of all upward currents of air, shifting their positions for this purpose. In an elastic fluid as the air, I imagine that the stream-lines, even over the sea, are far from horizontal. I believe the evidence of balloons over the sea goes to show this.

2. There is, to use a common expression, "flying and flying;" just as a man can skate without striking out, so can a bird give itself some support by quiet movements of wings and tail.

I may remark that kestrels keep fluttering their wings at short intervals while hovering; they are never still for long. So also terns and gulls, as seen from the fixed point of a cliff, are always moving and shifting in a quiet way, which may disguise both a seeking of upward currents and the quiet sort of "flying."

Cheitenham College

\section{Science and Theology}

Can you tell me by what right the authorities of Cooper's Hill Engineering College, who are in want of a Professor of Physics, make it a condition that he should "be a Protestant," and should "attend morning chapel and Sunday services with reasonable regularity, showing in this respect a good example to the students?" The institution is one supported by the State, and is surely bound to respect the principles which underlie the State's dealings with religious matters. The president (or whoever is responsible for these preposterous conditions) may have forgotten this fact; but I cannot believe that the present Government will allow an appointment to be made until all "religiuus" limitations are cancelled from its conditions. As the memorandum stands at present, it appears little short of insulting to scientific men.

C.

\section{Intelligence in Animals}

Mr. Grenfell's letter in NAture, vol. xxvii. p. 292, reminded me of a statement in vol. iii. p. 308 of Cook's last voyage, where Capt. King refers to the ordinary sagacity of bears, described in a "thousand stories" which he heard in 